\title{
DOSSIÊ
}

\section{Os 21 do XXI}

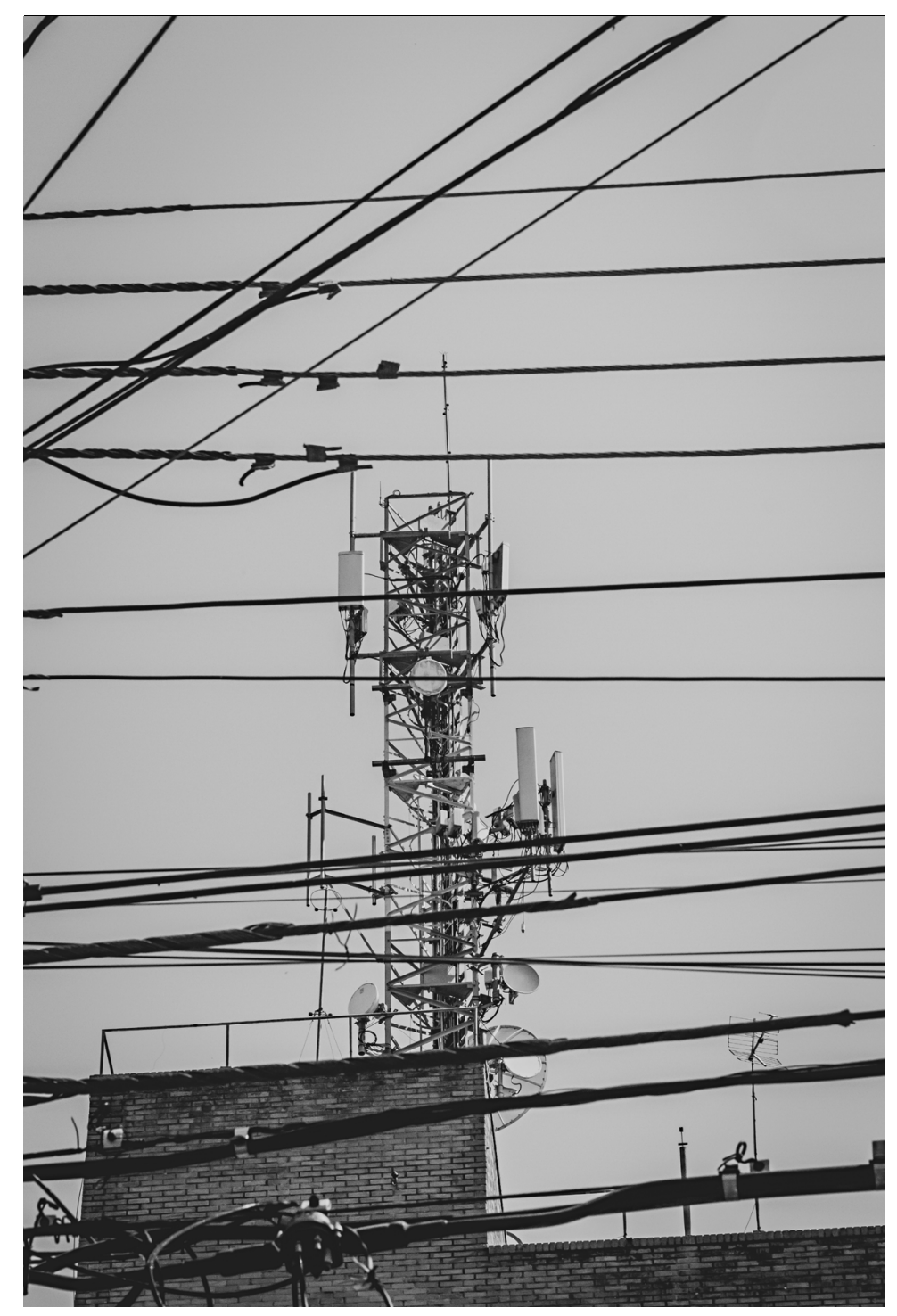

Interferências ( Foto de Kactus - Felipe Druda e Rodrigo Ferreira)

\section{ORGANIZAÇÃO | EDITED BY}

\section{Daniel Gambaro}

Universidade Anhembi Morumbi,

Programa de Pós-graduação em Comunicação

Eduardo Vicente

Universidade de São Paulo,

Programa de Pós-graduação em Meios e Processos Audiovisuais

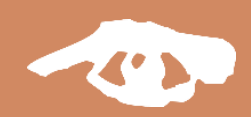

Novos Olhares | Vol.10 N.2 |jul-dez/2021 


\section{Apresentação do Dossiê: Práticas midiáticas nos primeiros 21 anos do século XXI}

Há 21 anos, quando o mundo se preparava para adentrar de vez no "terceiro milênio", o conjunto política, tecnologia e economia já prenunciava os desafios que vivemos globalmente. Superado o medo do bug do milênio, estávamos ainda vivendo o rescaldo da crise das "ponto com", que encerrou um ciclo de otimismo exagerado com o potencial de ganho de muitas empresas baseadas em internet que haviam surgido no final do século XX. Dois eventos, em 2001, coroam essa transformação: o gigante de tecnologia AOL compra a TimeWarner e se torna o maior conglomerado midiático do mundo - apesar do fracasso dessa fusão, se torna símbolo de um processo que se aprofunda nos anos seguintes -; na contramão do que simboliza tal acordo comercial, é fundada a Wikipedia, marco da capacidade da rede mundial em possibilitar uma "inteligência coletiva", baseada em redes de colaboração.

Nos primeiros anos deste século XXI, a World Wide Web ainda galgava espaço no nosso cotidiano, já extremamente permeado por conteúdos midiáticos. A indústria da música começava a sentir seus impactos, um movimento que anos depois chegaria ao cinema, à TV e ao rádio. Ainda não havíamos denominado como "plataformização" os processos em andamento, e os sites de redes sociais não mostravam toda sua potencialidade de influenciar as dinâmicas sociais, do consumismo às decisões políticas mais urgentes. Sentíamos, entretanto, a liquefação do tempo, a superfluidez da vida e a superficialidade das relações, como o filósofo Zygmunt Bauman claramente identificou.

Foi nesse contexto que vimos os telefones celulares se popularizarem, se difundirem, se transmutarem. Quando ganharam o prefixo smart, ao final do primeiro terço destes 21 anos, as culturas desta modernidade ultraconectada se mostraram como são: aceleradoras de processos que se imbricam em nossas conhecidas instituições, as dinamizam em fluxos que muitas vezes parecem nos fugir do controle. Como resultado, a impressão de excesso de informação e um profundo cansaço marca a nossa experiência cotidiana.

Nestes 21 anos de século XXI, vimos a tecnologia possibilitar conexões com realidades distantes. Vozes dissonantes ganharam espaço na rede - para o bem e para o mal. Nunca foi tão fácil disseminar a desinformação como hoje, amplificada por algoritmos baseados apenas em parâmetros comerciais. A inclusão e a diversidade caminham lado a lado com discursos de ódio. A política mundial, que parecia se abrir ao diálogo progressista, parece regredir na mesma medida em que avançaram os ataques desmedidos à imprensa tradicional.

Hoje vivemos uma pandemia que já toma dois destes 21 anos, e não parece ter uma data marcada para acabar. Uma crise sanitária mundial nos faz refletir sobre as possibilidades e os desafios da comunicação neste contexto altamente midiatizado. Não é possível compreendermos as disputas pela legitimidade dos 
discursos, hoje, sem analisarmos, antes, os passos que demos no escuro. Esse é o objetivo deste dossiê.

Os textos aqui incluídos permitem uma visão parcial, mas elucidadora, sobre práticas e processos vinculados a determinados meios de comunicação, instituições e processos culturais. São reflexões tomadas tanto do alto da maturidade acadêmica de alguns dos autores quanto das perspectivas críticas de pesquisadores iniciantes. O resultado é um rico percurso que, extrapolado dos objetos originais, permite ao leitor ou leitora fazer uma reflexão incondicional sobre nosso passado e nosso futuro.

No texto que abre este dossiê, Paul Long, como autor convidado, tenta responder às questões inerentes deste século refletidas em uma "economia em expansão" do patrimônio da música popular, a qual associa "à florescente agenda das políticas culturais e das indústrias criativas". A necessidade de "olhar para trás" em busca de valor, prática inequívoca no momento de confinamento e distanciamento por conta da pandemia, apenas tornou mais aparente um movimento que vem ganhando força desde o início deste século. Consciente de sua posição como pesquisador imerso no contexto dominante das produções em língua inglesa, Long descreve uma história dessa "indústria do patrimônio da música popular", e demonstra como artefatos ligados a essa prática da cultura ganham e produzem valor. Por meio de inúmeros exemplos de práticas de história, preservação e arquivo, tanto institucionais quanto emanadas de grupos e indivíduos, o autor perpassa diferentes pontos de inflexão, como: a construção de convenções culturais que permitem interpretar o passado; o papel dos consumidores e fãs na preservação do patrimônio; a "virada digital" e o prolongamento de ações de patrimônio em rede; a atuação de corporações na gestão de patrimônios; os modos como os discursos políticos dominantes afetam a percepção da história. $O$ trabalho de Paul, mesmo concentrado na música popular, oferece uma entrada para observarmos a herança e patrimônio da cultura pop neste início de século.

O segundo artigo, Um século em 21 anos: o rádio brasileiro sob a convergência (ou das fantasias eletrônicas à incerteza gerencial), escrito pelo professor Luiz Artur Ferraretto, identifica as transformações históricas do rádio nestes 21 anos - que tiveram o peso de todo um século. $O$ autor foge das "fantasias eletrônicas" calcadas em otimismo tecnológico exacerbado e demonstra a evolução dos conceitos em torno do rádio. Situa-o como uma instituição social recriada culturalmente em modo contínuo, o que permite a transição de sua caracterização, baseada no aparato técnico, para as formas "hipermidiática" e "expandida", em que se destacam a linguagem e os significados em torno da prática radiofônica. Em seu percurso, o autor discorre sobre três diferentes crises que afetam o negócio radiofônico: político-econômica, de modelo de negócios e de gestão. Inevitavelmente, Ferraretto precisa caminhar pelo contexto econômico-político brasileiro na tentativa de buscar as causas - e possíveis respostas - a essas crises que afetam não apenas o rádio, e sim os meios de comunicação social de um modo mais geral. Ao elencar os problemas do rádio, Ferraretto descreve os problemas da comunicação na sociedade brasileira em seu entrelaçamento com a conturbada realidade política dos últimos 20 anos, com as crises econômicas deste século e com a virada digital, que recondiciona a distribuição de verbas publicitárias.

Os efeitos da convergência midiática são, também, centrais na análise que Eneias Brum e Elisa Piedras fazem sobre o campo da publicidade. Em Transformações na publicidade: novas articulações entre o público e os produtores no campo publicitário, demonstram como as formas de contestação do público se tornam mais evidentes com as novas ferramentas de participação, exigindo atuações mais assertivas dos anunciantes e das agências publicitárias. Além disso, a própria publicidade fica mais suscetível às demandas sociais, imbricando-se mais profundamente nas disputas de sentido que emergem das transformações culturais, "restando explorar as possibilidades de mudanças estruturais". A esse fenômeno, os autores identificam respostas a partir de processos de dupla articulação que, numa ponta, tentam justificar discursos instituídos e, noutra ponta, acabam por incorporar as lutas e as demandas das minorias sociais. Dada a prevalência de atitudes do primeiro tipo, o texto "evidencia os obstáculos à reconfiguração do campo". 
Tais obstáculos que, na esfera do consumo, atrasam uma verdadeira rearticulação entre as diferentes vozes que se fazem ouvir nas mídias sociais, estão presentes também no âmbito do trabalho. Não obstante, como demonstra o próximo artigo, há exemplos de articulações importantes no sentido da luta por direitos. Nesse sentido, o artigo Insurgências on-line: Sobre o trabalho cultural e as lutas por reconhecimento enfatiza o papel das mídias sociais. Como explica Leandro de Paula, professor da Universidade Federal da Bahia (UFBA), há, neste começo de século, "algumas ambivalências que atravessam as relações entre tecnologia, trabalho e reconhecimento" à luz das transformações de uma "economia da informação" que alteram as formas de precarização do trabalho, ao mesmo tempo em que fomentam representações e lutas coletivas de trabalhadores por meio de plataformas midiáticas. $\mathrm{O}$ autor traz como caso para estudo uma das inúmeras formas de produção da economia criativa: o setor produtivo da música de concerto e a volatilidade de suas relações empregatícias. Mais especificamente, Leandro de Paula usa o caso SOS Orquestra Sinfônica Brasileira e sua manifestação em rede, em 2011, como ilustração a uma nova forma de ativismo e cooperação on-line. Os músicos, em protesto contra mudanças na gestão da Orquestra, disputam nas redes a narrativa pública capaz de sensibilizar formadores de opinião. Assim, o texto serve como um belo exemplo das "dinâmicas da reorganização do discurso público ocorridas na última década, com a sobreposição de expedientes e canais de vocalização de interesses".

Nos dois textos seguintes, a atenção se volta para o audiovisual. Em Diversidade e democratização no cinema e audiovisual brasileiro: um panorama de 2001 a 2021, Thiago Venanzoni nos dá pistas sobre a medida em que se espelha, na produção audiovisual brasileira, o discurso da diversidade, característica deste novo século. Discute, então, como os locais se tornam uma materialidade discursiva fundamental na realização do cinema mais recente, e argumenta que "há um conjunto de narrativas que se abriram ao coletivo em um novo contexto do cinema e do audiovisual e de suas políticas". O texto defende o avanço de "arranjos de produção", tanto por meio de políticas públicas diretas como no incentivo às produções coletivas, que emergem como forma viável para concretizar a descentralização da produção preconizada por ocasião da Lei do Audiovisual, em 2001.

Já Vicente Gosciola olha para o presente e o futuro das práticas audiovisuais em uma explanação profunda sobre a Volumetria audiovisual, isto é, a tridimensionalidade de "objetos virtuais", que implicam "não somente com os sentidos do ver e do ouvir, mas com uma gama de percepções que [...] vai além da tradicional metodologia de estudos do Cinema e da TV". O autor apresenta, então, um breve histórico da arte e da comunicação que sustenta esse movimento, o qual corresponde, por um lado, às tentativas do cinema em responder à concorrência com outros meios disputando atenção e, por outro, como no caso da recente proposta de "metaverso", novíssimas formas de virtualidade que alteram por completo o nosso estar no mundo. No percurso, são pontuadas técnicas e tecnologias (como drones, holografia e realidade virtual), elementos cuja naturalização no cotidiano fomentam as transformações desse campo de estudos, ainda em fase inicial, e que carece de mais teorização.

No texto que fecha o dossiê, Caio Dayrell Santos e Luiza Quental movem-se na descrição das pós-humanidades, um campo crítico que deriva das inquietações que emergem neste século. No texto, traçado em torno do pensamento da filósofa Rosi Braidotti, destaca-se, logo de início, que tal campo exige o "abandono do antropocentrismo", de uma ideia de "excepcionalidade da espécie humana que vê o humano como única medida possível para o mundo". No limite, vivemos entre "a 4a Revolução Industrial" e a "6ạ extinção": de um lado, os inumeráveis avanços tecnológicos e as mudanças econômicas e, de outro, o dano ecológico causado pela ação humana e insustentabilidade do capitalismo. Tal crítica evidencia como o sentimento pós-antropocêntrico serve ao capitalismo avançado, em seu caminho à indistinção entre o que é humano e o inumano, na transformação de absolutamente tudo em mercadoria e lucro. A resposta buscada por Santos e Quental, ainda apoiados em Braidotti, está no conceito grego de Zoé em substituição a Bios para expressar a vida, não mais em função de uma exclusividade humana, mas em torno de um "processo dinâmico, interativo e aberto, que age, reage e interage com o mundo que o rodeia e o fabrica... que procura envolver tanto epistemicamente quanto afetivamente outros atores além da humanidade". 
Esperamos que os textos reunidos neste dossiê, mais do que assinalar os 21 do XXI, permita cumprir a premissa expressa no nome desta revista: que sejam lançados novos olhares sobre as práticas comunicativas e culturais nesta era midiatizada. São, em nosso entender, pequenas peças que ajudam a desvendar a complexidade do período em que vivemos, e que substanciam uma discussão para repensarmos nossas articulações com as mídias e com o ambiente do século XXI.

Daniel Gambaro e Eduardo Vicente

Dezembro de 2021 